\title{
Intensitas Penyakit Blas (Pyricularia oryzae Cav.) pada Padi Varietas Ciherang di Lokasi Endemik dan Pengaruhnya terhadap Kehilangan Hasil
}

\author{
Tarkus Suganda", Endah Yulia, Fitri Widiantini dan Hersanti \\ Departemen Hama dan Penyakit Tumbuhan, Fakultas Pertanian, Universitas Padjadjaran \\ J1. Raya Bandung-Sumedang KM 21 Jatinangor 40600 \\ *Alamat korespondensi: tarkus.suganda@unpad.ac.id
}

\begin{abstract}
Disease intensity of blast disease (Pyricularia oryzae Cav.) of Ciherang rice variety at the endemic location and its effect on yield loss
\end{abstract}

Blast is one of the most important diseases of rice worldwide. Many countries have developed data on the intensity and yield loss due to blast disease, whereas Indonesia has no such data resulted from trial specifically designed to estimate blast intensity at the endemic location and its potential yield loss. Such data are needed for various purposes, such as for disease management policy and research background. A trial has been carried out at Desa Bojong, Kecamatan Cikembar, Kabupaten Sukabumi, a location where blast was endemic for years, using var. Ciherang that is known as susceptible and widely grown by farmers. Eight concentrations of fungicide of single as well as mix active ingredients were used to see the effects in suppressing blast diseases compared with of control. Trial used a Randomized Block Design with 5 replicates. The parameters observed were the intensity of leaf blast, neck blast and yield. The results showed that the disease intensity of var. Ciherang at the endemic location was $55.60 \%$ of leaf blast and $37.75 \%$ of neck blast. The potency of yield loss calculated was 3.65 ton/ha or equal with $61 \%$ of the average yield of var. Ciherang as described in its variety description. This number justifies the important of control measures of rice blast diseases.

Keywords: Blast disease intensity, var. Ciherang, Potency of yield loss

\begin{abstract}
ABSTRAK
Penyakit blas merupakan salah satu penyakit utama pada tanaman padi di seluruh dunia. Berbagai negara sudah memiliki data tentang intensitas dan kehilangan hasil padi oleh penyakit blas, sementara di Indonesia belum ada hasil pengujian yang khusus dirancang untuk melihat tingkat intensitas penyakit blas di daerah endemik dan potensi kehilangan hasil yang diakibatkannya. Data sejenis ini penting untuk berbagai keperluan antara lain untuk kebijakan pengendalian dan dasar pentingnya penelitian. Suatu percobaan telah dilakukan di Desa Bojong, Kecamatan Cikembar, Kabupaten Sukabumi yang merupakan daerah endemik penyakit blas selama bertahun-tahun, menggunakan var Ciherang yang merupakan varietas rentan namun populer ditanam petani. Delapan bahan aktif fungisida berbahan aktif tunggal dan majemuk digunakan untuk melihat pengaruh penekanannya dibandingkan kontrol. Percobaan menggunakan Rancangan Acak Kelompok dengan lima ulangan. Parameter yang diamati adalah intensitas penyakit blas daun dan blas leher malai serta hasil padi. Hasil percobaan menunjukkan bahwa intensitas penyakit blas pada tanaman padi var. Ciherang di daerah endemik adalah 55,60\% untuk blas daun, dan 37,75\% untuk blas leher malai. Potensi kehilangan hasil oleh gabungan penyakit blas pada var. Ciherang adalah 3,65 ton/ha atau setara dengan $61 \%$ kehilangan hasil jika dibandingkan terhadap rata-rata produksi var. Ciherang menurut spesifikasi varietas. Data ini menjustifikasi perlunya pengambilan tindakan pengendalian penyakit blas pada tanaman padi.
\end{abstract}

Kata Kunci: Intensitas penyakit blas, var. Ciherang, Potensi kehilangan hasil 


\section{PENDAHULUAN}

Penyakit blas yang disebabkan oleh jamur Pyricularia oryzae Cav. [sinonim Magnaporthe oryzae(Hebert) Barr] merupakan salah satu penyakit penting pada tanaman padi di seluruh dunia (Wang et al., 2014). Di Indonesia, penyakit blas sudah menyebar di hampir semua sentra produksi padi (Sudir dkk., 2014). Walaupun awalnya lebih dominan pada padi huma, namun saat ini, penyakit blas juga mulai menyerang tanaman padi di dataran rendah dan beririgasi di seluruh Indonesia. Beberapa areal persawahan beririgasi yang dilaporkan terserang penyakit blas adalah Subang, Karawang dan Indramayu di Jawa Barat; Pemalang, Pekalongan, Batang. Demak dan Jepara (Jawa Tengah), dan Lamongan, Jombang, Mojokerto, Pasuruan, Probolinggo dan Lumajang (Jawa Timur) (Sudir et al., 2013). Bukan hanya di Pulai Jawa, penyakit blas juga menyerang padi di Lampung, Sumetara Selatan, Jambi, Sumatera Barat, Sulawesi Tengah, Sulawesi Tenggara, dan Sulawesi Selatan, serta di Kalimantan Tengah dan Kalimantan Selatan (Amir dkk., 2003).

Hampir setiap negara penghasil padi sudah memiliki data tentang taksiran kehilangan hasil padi oleh penyakit blas. Menurut kompilasi Wang et al. (2014) kerugian hasil padi di Jepang berkisar antara 20-100\%; di Brasil mencapai 100\%, di India antara 5-10\%; Korea 8\%, China 14\% dan Filipina 50-85\%. Sementara kehilangan hasil padi oleh blas di Vietnam berkisar 38-83\%; di Itali antara 22-26\%, dan di Iran antara 20-80\%. Data demikian bermanfaat untuk berbagai keperluan, antara lain dalam pengambilan kebijakan pengendalian, dasar dari perlunya penelitian, prediksi produksi padi nasional, perlu tidaknya impor, dan lain-lain (Suganda, 2016).

Laporan tentang penyakit blas di Indonesia masih tentang luasan areal yang terserang dan taksiran intensitas serangan. Belum ada penelitian tentang taksiran kehilangan hasil padi akibat serangan penyakit blas berdasarkan penelitian yang dirancang khusus untuk membuat taksiran kehilangan hasil. Padahal data kehilangan hasil sangat penting untuk diketahui, mengingat data tersebut berguna bagi banyak pihak terkait (Suganda, 2016; Tsai, 1973). Contohnya, bagi Pemerintah, data kehilangan hasil akan berguna untuk pengambilan kebijakan dalam pengalokasian dana, baik dana penelitian maupun dana pencegahan dan penanggulangan; untuk prediksi produksi padi nasional, serta untuk prioritisasi kebijakan perlindungan tanaman. Sementara untuk para peneliti, data taksiran kehilangan hasil akan menjadi semacam motivasi dalam menetapkan prioritas penelitian (terutama dalam kaitannya untuk meyakinkan sponsor penyandang penelitian) dan sebagai rujukan bagi dunia ilmiah tentang penyakit blas di Indonesia. Data taksiran kehilangan hasil juga berguna untuk petani dalam melakukan justifikasi tindakan pengendalian, pengalokasian sumberdaya penegendalian, dan acuan harapan besarnya pendapatan dari hasil panen dengan memperhitungkan resiko dari ada atau tidaknya penyakit blas.

Studi tentang potensi kehilangan hasil produksi tanaman oleh penyakit sangat penting untuk dilakukan. Lyman (1918) sebagaimana disitir oleh James (1974) menyatakan bahwa bagaimana kita dapat meyakinkan petani tentang pentingnya suatu penyakit dan mengharap kucuran dana penelitian dari sponsor dan pemerintah jika kita hanya memberikan taksiran kasar tanpa melalui penelitian yang dirancang khusus.

Membuat penaksiran kehilangan hasil harus dilakukan melalui pengujian tersendiri. Taksiran kehilangan hasil tidak dapat dilakukan hanya berdasarkan perkiraan petani atau pengamatan sesaat, tetapi harus membandingkan antara tanaman yang diinokulasi dengan tanaman yang tidak terserang (Adipala et al., 1993). Menurut James \& Teng (1979), untuk melihat hubungan antara penyakit dengan hasil, pengujian harus dilakukan secara eksperimental yang melibatkan plot tanaman sehat sebagai kontrol atau plot yang benar-benar dikendalikan dengan perlakukan fungisida. Jika tidak diinokulasi buatan, maka lokasi pengujiannya pun harus dilakukan di lahan endemik penyakit tersebut.

Tulisan ini melaporkan hasil pengujian yang dilakukan terhadap padi varietas Ciherang, salah satu varietas padi yang ditanam secara luas dan dilaporkan rentan terhadap blas. Penelitian bertujuan untuk mengetahui intensitas serangan penyakit blas dan kaitannya dengan kehilangan hasil yang disebabkannya.

\section{BAHAN DAN METODE}

Percobaan dilaksanakan di lahan petani Desa Bojong Kecamatan Cikembar, Kabupaten 
Sukabumi. Lokasi ini sudah bertahun-tahun digunakan untuk penelitian penyakit pada tanaman padi oleh berbagai pihak dan merupakan daerah endemik penyakit blas. Varietas padi yang digunakan adalah var. Ciherang, sedangkan fungisida yang digunakan terdiri atas fungisida berbahan aktif tunggal dan fungisida berbahan aktif majemuk. Pemilihan bahan aktif fungisida didasarkan kepada ketersediaannya di pasaran. Konsentrasi yang dipakai adalah konsentrasi anjuran untuk masing-masing fungisida.

Percobaan menggunakan Rancangan Acak Kelompok (RAK) yang terdiri atas 8 perlakuan dengan 5 ulangan dengan ukuran petak 5 x $5 \mathrm{~m}$ dan jarak antar petak $1 \mathrm{~m}$. Fungisida diaplikasikan setiap minggu. Pada perlakuan kontrol tidak dilakukan penyemprotan fungisida. Cara budidaya dan pemeliharaan tanaman disesuaikan dengan praktik yang biasa dilakukan oleh petani setempat. Pemupukan dilakukan 3 kali yaitu saat umur padi 10 hari setelah tanam (HST) dengan $150 \mathrm{~kg}$ NPK Ponska $+50 \mathrm{~kg}$ urea per ha, ditambah insektisida Furadan 3 G. Pemupukan kedua diberikan saat umur padi 25 HST dengan 100 kg Ponska; dan pemupukan ketiga saat umur 45 HST dengan Ponska $50 \mathrm{~kg}$ + urea $50 \mathrm{~kg} / \mathrm{ha}$. Tanaman percobaan tidak diinokulasi buatan karena lokasi percobaan merupakan daerah endemik, dimana penyakit blas selalu menyerang pertanaman padi.

\section{Pengamatan}

Pengamatan dilakukan terhadap intensitas penyakit, berupa blas daun (leaf blast) dan blas leher malai (neck blast). Pengamatan dilakukan seminggu sekali, namun data yang dianalisis adalah data pengamatan terakhir, bersamaan dengan kemunculan gejala blas malai. Intensitas penyakit (IP dalam \%) blas daun dihitung menggunakan rumus sebagai berikut:

$$
\mathrm{IP}=\frac{\sum(\mathrm{nv})}{\mathrm{NV}}
$$

Keterangan:

IP = intensitas kerusakan tanaman

$\mathrm{n}=$ jumlah tanaman dalam setiap kategori kerusakan

$\mathrm{v}=$ nilai skala tiap kategori kerusakan

$\mathrm{N}=$ jumlah tanaman contoh yang diamati

$\mathrm{V}=$ nilai skala tertinggi dari kategori kerusakan
Skala yang digunakan untuk menilai

kategori kerusakan adalah:

\begin{tabular}{cl}
\hline Skala & \multicolumn{1}{c}{ Deskripsi } \\
\hline 0 & Tidak ada gejala \\
\hline 1 & Daun terinfeksi $1-10 \%$ \\
\hline 2 & Daun terinfeksi $11-20 \%$ \\
\hline 3 & Daun terinfeksi $21-30 \%$ \\
\hline 4 & Daun terinfeksi $31-40 \%$ \\
\hline 5 & Daun terinfeksi $41-50 \%$ \\
\hline 6 & Daun terinfeksi $>50 \%$ \\
\hline
\end{tabular}

Untuk menentukan berat penyakit blas leher malai digunakan persentase jumlah malai terinfeksi dalam satu rumpun tanaman contoh (disease incidence) dibandingkan terhadap total malai yang ada. Dalam satu plot perlakuan, diambil 25 rumpun tanaman contoh yang ditetapkan menggunakan pola diagonal.

\section{Pengolahan dan Analisis Data}

Data pengamatan dianalisis menggunakan program SPSS ver 21 untuk menghitung Uji Fisher. Jika hasil Uji Fisher menunjukkan adanya perbedaan secara statistik, untuk melihat perbedaan antar perlakuan dilanjutkan dengan pengujian menggunakan Uji Jarak Berganda Duncan pada taraf nyata $5 \%$.

\section{HASIL DAN PEMBAHASAN}

Data hasil pengujian (Tabel 1) menunjukkan bahwa lokasi pengujian terkonfirmasi sebagai daerah endemik, karena tanpa inokulasi buatan, intensitas penyakit blas terlihat cukup tinggi $(55,60 \%)$ sebagaimana terlihat pada petak kontrol. Demikian pula var. Ciherang terbukti merupakan salah satu varietas padi yang termasuk dalam kategori varietas yang rentan terhadap penyakit blas. Data pada Tabel 1 juga menunjukkan bahwa pengaplikasian berbagai fungisida yang diuji, baik yang berbahan aktif tunggal maupun yang berbahan aktif campuran, dalam konsentrasi anjurannya masing-masing, secara nyata menekan intensitas penyakit blas daun (leaf blast), namun tidak demikian hasilnya terhadap intensitas blas leher malai (neck blast).

Data hasil pengujian (Tabel 1) menunjukkan bahwa tidak semua bahan aktif fungisida yang diuji mampu menekan intensitas blas leher malai. Ada yang mampu menekan secara sangat nyata berbeda dengan kontrol, yaitu Metalaksil 34 g/l dan Trisiklazol 525 g/l, dan ada 
yang penekanannya berbeda nyata dengan kontrol, yaitu fungisida berbahan aktif tunggal Isoprotiolan $400 \mathrm{~g} / \mathrm{l}$, serta fungisida berbahan campuran trisklazol $225 \mathrm{~g} / \mathrm{l}+$ Azoksistrobin $75 \mathrm{~g} / \mathrm{l}$. Secara umum, hasil penelitian ini menunjukkan bahwa fungisida campuran dua bahan aktif tidak menjadi jaminan akan lebih efektif dibandingkan fungisida berbahan aktif tunggal dalam menekan intensitas penyakit blas pada tanaman padi. Pencampuran lebih dari satu bahan aktif fungisida memang tidak menjamin akan menjadi lebih efektif, melainkan lebih dimaksudkan untuk menekan atau memperlambat kemunculan resistensi jamur patogen terhadap bahan aktif fungisida (FRAC, 2010).

Tabel 1. Intensitas penyakit blas daun dan blas leher malai dan produksi padi var. Ciherang di daerah endemik yang diberi aplikasi berbagai fungisida.

\begin{tabular}{|c|c|c|c|c|c|}
\hline \multirow{2}{*}{ No. } & \multirow{2}{*}{ Bahan aktif } & \multirow{2}{*}{ Konsentrasi } & \multicolumn{2}{|c|}{ Intensitas penyakit (\%) } & \multirow{2}{*}{$\begin{array}{c}\text { Hasil } \\
\text { (kg/plot) }\end{array}$} \\
\hline & & & Blas daun & Blas leher malai & \\
\hline 1 & Metalaksil $34 \mathrm{~g} / 1$ & $1,5 \mathrm{~g} / 1$ & $8,53^{* *}$ & $6,64^{* *}$ & $24,44^{*}$ \\
\hline 2 & Trisiklazol $525 \mathrm{~g} / 1$ & $1 \mathrm{ml} / 1$ & $6,00^{* *}$ & $8,41^{* *}$ & $20,56^{*}$ \\
\hline 3 & Isoprotiolan $400 \mathrm{~g} / 1$ & $2 \mathrm{ml} / 1$ & $4,89^{* *}$ & $10,04^{*}$ & $20,96^{*}$ \\
\hline 4 & $\begin{array}{l}\text { Flusilazole } 125 \mathrm{~g} / 1+ \\
\text { Carbendazim } 250 \mathrm{~g} / 1\end{array}$ & $1,5 \mathrm{ml} / \mathrm{l}$ & $2,67^{* *}$ & 30,28 & 18,35 \\
\hline 5 & $\begin{array}{l}\text { Diffeconazole } 150+ \\
\text { Propiconazole } 150\end{array}$ & $2,25 \mathrm{ml} / \mathrm{l}$ & $5,22^{* *}$ & 44,28 & 15,48 \\
\hline 6 & Difekonazol 250 g/l & $2 \mathrm{ml} / \mathrm{l}$ & $5,00^{* *}$ & 30,86 & 14,95 \\
\hline 7 & $\begin{array}{l}\text { Trisiklazol } 225 \mathrm{~g} / 1+ \\
\text { Azoksistrobin } 75 \mathrm{~g} / 1\end{array}$ & $1 \mathrm{ml} / 1$ & $6,00^{* *}$ & $10,87^{*}$ & $20,56^{*}$ \\
\hline 8 & Kontrol & - & 55,60 & 37,75 & 15,32 \\
\hline
\end{tabular}

Keterangan: *Berbeda nyata dengan kontrol; ${ }^{* *}$ Berbeda sangat nyata dengan kontrol, menurut Uji Jarak Berganda Duncan taraf nyata $5 \%$.

Hasil pengujian ini juga menunjukkan bahwa pada umumnya, bahan aktif yang efektif terhadap penyakit blas daun tidak secara otomatis efektif juga dalam menekan blas leher malai. Hal yang sama dilaporkan pula oleh Ghazanfar et al. (2009) bahwa bahan aktif yang sama memiliki efek yang berbeda terhadap blas daun dan blas leher malai. Beberapa peneliti juga melaporkan bahwa intensitas penyakit blas leher malai selalu lebih tinggi dibandingkan dengan intensitas blas daun oleh jenis fungisida yang sama (Dutta et al., 2012; Ghazanfar et al., 2009).

\section{Potensi Kehilangan Hasil Akibat Penyakit Blas}

Berdasarkan data pada Tabel 1, dapat diketahui bahwa potensi kehilangan hasil padi var. Ciherang oleh penyakit blas (gabungan antara blas daun dengan blas leher malai) mencapai $9,12 \mathrm{~kg}$ gabah kering giling per plot (hasil pada perlakuan dengan Metalaksil dikurangi hasil gabah pada perlakuan kontrol). Hasil ini setara dengan 3,65 ton/ha, yang diperoleh dari kalkulasi $10.000 \mathrm{~m}^{2} /(5 \mathrm{x}$ $5 \mathrm{~m}^{2}$ ) dikalikan dengan 9,12 kg/plot.
Hasil pengujian ini memberikan justifikasi bahwa selama belum ditemukan cara pengendalian yang lain, pengaplikasian fungisida mampu menekan kehilangan hasil padi oleh penyakit blas sebesar 3,65 ton/ha. Hal ini sejalan dengan laporan Sood \& Kapoor (1997), Tirmali et al. (2001), Prabhu et al. (2003) dan Ghazanfar et al. (2009), yang menyatakan bahwa pengaplikasian fungisida mampu meningkatkan hasil. Namun istilah yang lebih tepat seharusnya adalah telah terjadi 'penekanan kehilangan hasil' dan bukan 'peningkatan hasil'.

Pada pengujian ini, inokulum atau sumber penyakit berasal dari alam tanpa dilakukan inokulasi buatan. Dengan demikian, intensitas penyakit dalam percobaan ini merupakan hasil infeksi alami sehingga data yang disajikan bukan sebagai model dari kemunculan suatu outbreak. Intensitas penyakit yang terjadi adalah intensitas yang mungkin diperoleh sebagai infeksi alami pada daerah endemik.

Data hasil pengujian ini menunjukkan bahwa jika petani tidak melakukan tindakan pengendalian, maka potensi kehilangan hasil yang akan dideritanya akan berkisar 3,65 ton/ha. Jika 
menurut deskripsi pada var. Ciherang potensi produksinya adalah 8,5 ton/ha, dan rata-rata produksinya adalah 6 ton/ha (Balitbangtan, 2016), maka kehilangan hasil oleh penyakit blas sebesar 3,65 ton/ha tersebut setara dengan 61\%. Dengan demikian, tindakan pengendalian dengan fungisida dapat dijustifikasi sebagai tindakan yang tepat dalam mencegah kehilangan hasil padi oleh penyakit blas. Menurut Penisi (2010), hasil padi yang hilang oleh penyakit blas, jika tidak dikendalikan dapat menjadi pangan yang cukup bagi 60 juta orang. Artinya, penyakit blas pada padi wajib dikendalikan karena jika tidak, maka petani berpotensi kehilangan 61\% dari hasil padi yang seharusnya diperolehnya.

\section{SIMPULAN}

Dari hasil pengujian ini diperoleh simpulan sebagai berikut:

1. Intensitas penyakit blas pada tanaman padi var. Ciherang di daerah endemik adalah 55,60\% untuk blas daun, dan 37,75\% untuk blas leher malai.

2. Potensi kerugian hasil oleh penyakit blas pada var. Ciherang adalah 3,65 ton/ha atau setara dengan 61\% kehilangan hasil jika dibandingkan terhadap rata-rata produksi var. Ciherang.

\section{DAFTAR PUSTAKA}

Adipala, E, PE Lipps, and LV Madden. 1993. Use of disease assessment methods in predicting yield loss due to nothern leaf blight of maize. African Crop Science Journal. 1(2):159-173.

Amir, M, Santoso, A Nasution, dan B Kusdianto. 2003. Pemetaan Pyricularia grisea di Daerah Endemik Blas di Sentra Produksi Padi Sawah dan Padi Gogo. Laporan Akhir Tahun Balitpa, Balitbangtan, Departemen Pertanian.

Balitbangtan. 2016. Varietas Ciherang. Tersedia online pada: www.litbang.pertanian.go.id. Badan Litbang Pertanian. (diakses 12 September 2016).

Cooke, BM. 2006. Disease assessment and yield loss. Chapter 2 in The Epidemiology of Plant Diseases $2^{\text {nd }}$ Ed. (BM Cooke, DG Jones and B Kaye, eds). Springer. The Netherlands.

Dutta, D, S Saha, DP Ray, and MK Bag. 2012. Effecr of different active fungicides molecules on the management of rice blast disease. Int. J. Agric. Env. Biotech. 5(3):247-251.

FRAC. 2010. Recommendations for Fungicide Mixtures. Available online at: http://www.frac.info/docs/defaultsource/publications/frac-recommendationsfor-fungicide-mixtures/frac-

recommendations-for-fungicide-mixtures--january-2010.pdf?sfvrsn=4. Fungicide Resistance Action Committee. (accessed 15 August 2016).

Ghazanfar, MU, W Wakil, ST Sahi and SI Yasin. 2009. Influence of various fungicides on the management of rice blast disease. Mycopath. 7(1):29-34.

James, WC and PS Teng. 1979. The quantification of production constrains associated with plant disease. Applied Biology. 4:210-266.

James, WC. 1974. Assessment of plant disease and losses. Annual Review of Phytopathology. 12:27-48.

Kuyek, D. 2000. Blast, Biotech and Big Business: Implications of Corporate Strategies on Rice Research in Asia. Available online at: http://www.grain.org/publications/reports/b last.htm. (accessed 20 August 2016).

Pennisi, E. 2010. Armed and dangerous. Science. 327 (5867):804-805.

Prabhu, AS, MC Filippi, and FJP Zimmermann. 2003. Cultivar response to fungicide application in relation to rice blast control, productivity and sustainability. Pesq. Agropec. Bras., Brasília. 38:11-17.

Sood, GK and ASB Kapoor. 1997. Efficacy of new fungicides in the management of rice blast. Plant Dis. Res. 12:140-142.

Sudir, A Nasution, Santoso, dan B Nuryanto. 2014. Penyakit blas Pyricularia grisea pada tanaman padi dan strategi pengendaliannya. Iptek Tanaman Pangan. 9(2): 85-96.

Suganda, T. 2016. Pentingnya penelitian tentang penaksiran kehilangan hasil akibat organisme pengganggu tanaman. [Abstract]. Seminar Plant Protection Day dan Seminar Nasional II, 20 Oktober 2016. Universitas Padjadjaran.

Tirmali, AM, SB Latake, and NJ Bendra. 2001. Evaluation of new fungicides for control of blast disease of rice. J. Maharashtra Agri. Univ. 26:197-198.

Tsai, WH. 1974. Assessment of Yield Losses Due to Rice Sheath Blight at Different Inoculation 
Stages. Serial No. (Q) 661. Department of Plant Pathology, UPCA. Available online at: http://ir.tari.gov.tw:8080/bitstream/3452100 00/1324/1/journal_arc_23-3-4.pdf. (accessed 20 August 2016).

Wang, X, S Lee, J Wang, J Ma, T Bianco, and Y Jia. 2014. Current advances on genetic resistance to rice blast disease. Chapter 7 in
Rice-Germplam, Genetics and Improvement (W Yan and J Bao, eds.). Available online at: http://www.intechopen.com/books/ricegermplasm-genetics-and-improvement/ current-advances-on-genetic-resistance-torice-blast-disease. (diakses 12 September 2016). 